\title{
AS MINI-HISTÓRIAS ENQUANTO POSSIBILIDADE DE EXPERIMENTAR UM ENCONTRO COM A ARTE
}

\author{
MINI-STORIES AS THE POSSIBILITY OF EXPERIENCING NA ENCOUNTER WITH ART
}

https://orcid.org/0000-0003-2669-2992 Viviane Zimermann Heck ${ }^{\text {A }}$

${ }^{\text {A }}$ Universidade Federal de Pelotas (UFPEL), Pelotas, RS, Brasil

Recebido em: 29 dez. 2021 | Aceito em: 3 jan. 2022 Correspondência: Viviane Zimermann (vivizheck@gmail.com)

\begin{abstract}
Resumo
O presente artigo tem como objetivo, a partir das mini-histórias, oportunizar um encontro com a Arte. Utilizarei como referencial o Prof. Dr. Paulo Fochi (2017), bem como minha experiência enquanto professora participante do OBECI (Observatório da Cultura Infantil) entre os anos de 2015 a 2018 e as ideias de Jorge Larrosa (2015) sobre a Experiência. As mini-histórias são narrativas que fazem uso da palavra e da imagem e tornam especial algo que poderia passar despercebido no cotidiano da escola da infância. Portanto, caracterizar essa documentação, bem como o seu processo de produção, permite compreender e legitimar a ação de escrever como uma maneira do professor expressar-se, de fazer do seu pensar uma forma de dizer sobre o que lhe toca, o que lhe move e como percebe sua prática junto das crianças.
\end{abstract}

Palavras-chave: Mini-histórias; Escrita; Experiência; Arte.

\section{Abstract}

This article aims, from the mini-stories, to provide an opportunity for an encounter with Art. I will use Prof. Dr. Paulo Fochi (2017), as well as my experience as a teacher participating in the OBECI (Observatory of Children's Culture) between 2015 and 2018 and the ideas of Jorge Larrosa (2015) on Experience. The mini-stories are narratives that make use of the word and the image and make something special that could go unnoticed in the daily life of the childhood school. Therefore, characterizing this documentation, as well as its production process, allows us to understand and legitimize the action of writing as a way for the teacher to express himself, to make his thinking a way of saying about what touches him, what moves him. and how you perceive your practice with children.

Keywords: Mini-stories; Writing; Experience; Art. 


\section{O que são as mini-histórias?}

(...) pequenos relatos, alguns com um passado denso, outros com um longo futuro e, alguns, simples instantes(...) uma homenagem à capacidade das crianças de construir histórias maravilhosas

Altimir

As mini-histórias ${ }^{\mathrm{i}}$ são textos narrativos que visam compartilhar momentos da vida das crianças na escola da infância. São "pescados”, ou seja, não são planejados pelo professor, mas acontecem em momentos pensados, em espaços acolhedores, em situações do cotidiano nas quais o olhar atento do professor "pesca" cenas interessantes, histórias de vida que acontecem na escola e que, narradas com imagens e texto, permitem ser compartilhadas, refletidas e valoradas por toda comunidade escolar.

O professor que narra, narra a infância e narra-se também, constituindo, assim, um processo no qual produz pensamentos sobre o que vê em sua prática com as crianças, o que percebe nas interações entre elas, nas pesquisas que acontecem nos contextos organizados. Enfim, narra as ações protagonistas das crianças, revelando a si e aos leitores o valor nas ações dos meninos e das meninas.

As mini-histórias também se caracterizam como uma forma de documentar, com o uso de imagens e texto, tornando visível os percursos de aprendizagem das crianças. Assim sendo, é possível afirmar que, na prática do professor, elas representam uma escolha entre várias possíveis de comunicar e valorar o cotidiano perante si, o próprio professor, e também aos olhos das crianças e adultos da comunidade escolar na qual a escola está inserida.

Conforme Fochi (2017, p. 99):

A ideia das mini-histórias está ligada à revisitação dos observáveis produzidos pelos professores no cotidiano da Educação Infantil. A partir de uma breve narrativa imagética e textual, o adulto interpreta esses observáveis de modo a tornar visível as rapsódias da vida cotidiana. Essas rapsódias são fragmentos poéticos, portanto sempre episódicos que, quando escolhidos para serem interpretados e compartilhados, ganham valor educativo. Esse exercício de olhar para um material que já existe, buscando extrair sentidos, é uma experiência ímpar de autoformação do professor, pois implica fazer uma escolha dentre tantas. Uma escolha que, de alguma forma, o próprio professor faz parte. E fazer isso implica deixar algo de fora, não escolher. A mini-história narra a criança, colocando-a em evidência, ou seja, suas ações são valoradas e refletidas. O texto escolhido, as imagens e a escrita auxiliarão para evidenciar a história dessa criança, respeitando sua individualidade e tornando especial algo que poderia passar despercebido.

Para a produção das mini-histórias, o professor debruça-se sobre as imagens e escritas

Revista Interinstitucional Artes de Educar. Rio de Janeiro, V.8, N.1 - pág. 287-302 jan-maio de 2022: "Por uma pedagogia macunaímica" - DOI: 10.12957/riae.2022.65332 
(observáveis) que produz sobre as ações das crianças e faz escolhas de acordo com o que esses observáveis lhe tocam e as histórias que suscitam. Assim, com um olhar sensível e uma escuta ativa, busca perceber nas ações das crianças o que lhes move, o que pesquisam, o que narram, muitas vezes sem palavras, mas em olhares, em ações que se repetem e que, justamente por isso, contam algo da criança, algo que narra sua individualidade e que o professor, por meio de fotografias e texto, tem a possibilidade de tornar especial, evidenciando a riqueza do cotidiano da escola de Educação Infantil que, muitas vezes, ainda é percebida como inferior em relação aos demais níveis de ensino ou então atrelada ao assistencialismo.

Assim, num primeiro momento, o professor volta às imagens que reuniu e escolhe dentre elas as que possuem histórias a contar, possuem valor, tocam a ele e se põe a narrar com todos os seus sentidos envolvidos: nesse momento, pode ou não acontecer a experiência de um encontro com a Arte, oportunizando um momento no qual seus sentidos, seus pensamentos, suas formas de existir e ser professor são expressadas por meio da palavra escrita. Nesse processo, ele poderá despir-se, brevemente, de julgamentos, e assim, refletir sobre as crianças e sobre ele também. Aqui, além da possibilidade de narrativa das crianças, a mini-história oportuniza também o papel de um professor que se narra, e por narrar-se permite-se experimentar a Arte da palavra, pois como afirma Larrosa (2015, p.16-17):

\footnotetext{
...as palavras produzem sentido, criam realidades e, às vezes, funcionam como potentes mecanismos de subjetivação. Eu creio no poder das palavras, na força das palavras, creio que fazemos coisas com as palavras e, também, que as palavras fazem coisas conosco. As palavras determinam nosso pensamento porque não pensamos com pensamentos, mas com palavras, não pensamos a partir de uma suposta genialidade ou inteligência, mas a partir de nossas palavras. E pensar não é somente "raciocinar" ou "calcular" ou "argumentar", como nos tem sido ensinado algumas vezes, mas é sobretudo dar sentido ao que somos e ao que nos acontece. (grifos do autor)
}

Nessa perspectiva, busco compreender o quanto a prática das mini-histórias pode tornarse um encontro de experimento com a Arte para o professor e quiçá oportunizar esse encontro também aos leitores que poderão interagir com o texto produzido e, assim, também viver uma experiência com as possibilidades da leitura literária, o que permite um encontro com a vida.

\section{As mini-histórias enquanto possibilidade de viver e experimentar o encontro com a Arte}

Para pensar as mini-histórias enquanto experiência com a Arte, utilizo o conceito de experiência de Larrosa (2015, p. 18) “A experiência é o que nos passa, o que nos acontece, o que nos toca. Não o que se passa, não o que acontece, ou o que toca. A cada dia se passam muitas coisas, porém, ao mesmo tempo, quase nada nos acontece”. Esse pensar dialoga com o que acredito que a escrita das mini-histórias seja capaz de possibilitar a quem a produz e a quem 
ela se destina também: pais, crianças e outros professores.

Pensar em escrita de mini-histórias enquanto experiência com a Arte pressupõe que esse momento seja, em primeiro lugar, um tempo no qual o professor se encontra com o que lhe toca de sua prática e das ações das crianças e, ao voltar o olhar para os observáveis do seu cotidiano (imagens e escritas), sentirá o desejo de escrever sobre eles, pois essa escrita lhe permite o pensar, o dialogar com o que lhe move e instiga. Ao escrever, o professor tem a oportunidade de produzir pensamento, expressar seu olhar a partir das ações das crianças e do que elas podem significar, agregando um valor às mesmas. A própria escolha das imagens conversa com o que toca o professor, o que lhe chama atenção das ações e pesquisas das crianças e pode estar relacionado com suas crenças, leituras e olhares para a infância. Além disso, ainda podem conversar com a infância do próprio professor.

O professor, ao narrar a cena, por meio da escolha das fotos, bem como do texto, reflete sobre sua percepção de criança, sobre a caminhada e sobre as características das crianças na sua individualidade. Esse processo permite conhecer mais as crianças, seus gostos, ações que se repetem no cotidiano e parcerias de brincadeiras e descobertas. Ou seja, permite ao professor conhecer mais seu grupo de crianças.

Ao pensar sobre a história que irá contar, o professor inicia sua narrativa e, por vezes, um viés poético faz-se presente, pois esse permite o "contar mais com menos". Sendo assim, a escolha das palavras, a disposição das mesmas no texto, bem como a escolha por algumas metáforas e/ou uma escrita mais subjetiva permite tanto ao professor como ao leitor encontrarse no texto. Além disso, o professor também necessita ter ciência que sua narrativa sempre será uma leitura da realidade, pois ele apenas faz um relato do que imagina as crianças estarem vivenciando. Assim, escreve uma história que pode ou não ser a verdade. Essa certeza apenas pertence aos participantes da própria cena. Nesse sentido, conhecer as crianças e a forma como interagem com os outros e com o mundo permite, com mais facilidade, observar e narrar imaginando uma história por detrás de uma sequência fotográfica.

Ao narrar as muitas infâncias, o professor autor também acaba por narrar-se, pois torna visível, em sua escrita, uma percepção de criança e de escola. Evidencia também sua postura frente a essa infância. Ao olhar para a criança em suas ações, em seu contexto, também reflete sobre o seu papel nessa caminhada, o quanto contribui e o quanto necessita modificar algumas de suas ações. Assim, o professor pesquisa a criança e pesquisa a si próprio. Ao pensar o processo, acaba por refletir-se enquanto profissional, permitindo-se um aprender pela prática e também pelos pensamentos que são desencadeados por ela, permeados por uma bagagem 
teórica. Dessa forma, esse processo possibilita o aprender sobre ser professor de crianças bem pequenas num contexto no qual esse nível de ensino, muitas vezes, é colocado à margem, denotando, ao mesmo, menor valor.

As mini-histórias, muitas vezes, provocam no leitor a percepção de um novo ponto de vista, ou seja, possibilitam perceber a cena de uma forma diferente por meio da narrativa. A escrita, por vezes, torna especial algo que, num primeiro momento, poderia parecer banal. Com a escrita, é possível evidenciar a individualidade das crianças num espaço coletivo, onde são vistas, em grande parte do tempo, como grupo.

Narrar infâncias, suas especificidades, suas marcas, e também narrar-se enquanto profissional são elementos consequentes da prática da escrita das mini-histórias. Essas se constituem como material de pesquisa para crianças, professores e comunidade em geral. Revelam as experiências das crianças e a sua riqueza. A escrita, enquanto hábito do professor, permite que esse se torne autor e construa, por meio da práxis, um caminho a ser trilhado na Educação Infantil.

A produção de mini-histórias legitima também o trabalho pedagógico na Educação Infantil - etapa creche -, pois reconhece como currículo os momentos do cotidiano que necessitam de reflexão e precisam ser problematizados, refletidos e, por vezes, modificados. Problematiza o que pode estar naturalizado.

O que me leva a propor a escrita das mini-histórias, descrita anteriormente, enquanto experiência em Arte para o professor, é a possibilidade de reflexão sobre a sua vida, em especial sobre sua profissão e o quanto essa escrita pode ser dialógica com o sujeito que a produz. Assim, por meio da narrativa, o professor traz reflexões da sua individualidade e narra um coletivo, essa narrativa conversa com um contexto social, no caso a infância que é retratada e pode ser refletida na infância dos leitores que apreciam a mini-história enquanto aporte de Arte.

Assim, entendo que a escrita pode provocar um olhar para nós mesmos e esse olhar interfere no cotidiano da Educação Infantil, nos contextos que organizamos e na forma que compreendemos e valoramos as ações e narrativas das crianças. Escrever para encontrar e ver o que próximo está, mas que, por vezes, insistimos em desviar nosso olhar por inúmeras razões. E é esse olhar para si e para o outro que percebe nas perguntas a possibilidade de desconstruir certezas e desvelar possibilidades de caminhos, efetivando um olhar de cuidado ao outro e a si.

Escritas que não se pretendem prescritivas, mas que potencializam a suspensão/interrogação de certas verdades e palavras (co)engendradas nas práticas educacionais. Um exercício de pensar o processo de produção de nossas escritaspesquisas no campo educacional ao mesmo tempo em que somos convocados ao 
exercício estético do cuidar de si mesmo. (MUNIZ, Adriana Werneck Russo; BASTOS, Karine Oliveira; AMADO, Luiz Antônio Saléh, 2020, p.5)

Os pensamentos que as mini-histórias suscitam tanto no professor que as produz, como nos leitores que entram em contato com elas, sempre são de acordo com as histórias de vida de cada sujeito. Por isso, também, algumas tocam mais uns, enquanto outras mais outros leitores.

Dessa forma, a escrita das mini-histórias nos permite pesquisar e pensar sobre o que não sabemos, sobre o que nos causa dúvida, interesse, nos convoca o olhar, faz pensar... nos consegue transformar. Eis uma possibilidade que percebemos na escrita das mini-histórias: ela conversa com a vida do professor, lhe permite o devaneio e, por meio dessa experiência, o torna diferente, lhe confere um novo olhar, lhe afeta.

\begin{abstract}
...experimentar afetos sinaliza a enunciação de outras formas de agir a partir dos modos de expressão que vamos percorrendo. Quando afetados pelas audições e visões, gostos e cheiros, toques de vidas que nos forçam a pesquisar na historicidade de um tempo que acontece, percebemos que nossas questões são feitas de vidas. Assim, exercitamos uma ética e expandimos nosso conhecer nas relações de uma vida de todos em nós, de uma vida de si com todos. Imanência de relações no corpo que cria passagens com o que força a experimentar nosso pensamento: afectos e perceptos que já não são de um ou de outro, mas da vida. Não precisamos mais temer o processo de estarmos afetados pelo acontecimento no ato de pesquisar, pois o que antes era dado como "ponto fraco" do pesquisador, agora marca uma condição indispensável do processo de pesquisar: a capacidade de afetar e afetar-se para que se criem os modos de expressar os sentidos de uma pesquisa. (LAZZAROTTO, Gislei D. R.; CARVALHO, Julia D. In: FONSECA, Tania Mara Gali; NASCIMENTO, Maria Lívia;_MARASCHIN, Cleci. (ORG) 2012, p24-25, grifos do autor)
\end{abstract}

E por afetar-se sobre o que vê de especial nas ações das crianças, experimenta encontrarse com a Arte em forma de palavra, vivenciando momentos nos quais pode se expressar enquanto ser professor e pessoa que se impregna do cotidiano e, no olhar minucioso, encontra nas ações das crianças as respostas para suas muitas perguntas.

\title{
Mini-histórias de uma caminhada: experimentando o encontro com a Arte
}

Escolho, a seguir, uma sequência de mini-histórias oriundas de duas sessões de construção com elementos não estruturados que aconteceram nos meses de agosto e setembro de 2021.Essas sessões foram organizadas com um número reduzido de crianças ( 2 a 4), com idades entre 2 e 3 anos e aconteceram em um espaço e tempo planejados e organizados previamente por mim professora com o intuito de enriquecer as experiências das crianças em relação ao que vinham pesquisando: possibilidades de construção. As primeiras imagens contextualizam o momento inicial da sessão no qual organizei elementos não estruturados que possibilitassem às crianças a ideia da construção. Destaco que a sessão acontece semanalmente e é organizada a partir do olhar da professora que percebe nas ações e investigações das crianças 
um interesse pela ação de construir.

Dessa forma, a primeira sessão, cuja finalidade era oferecer elementos com os quais as crianças pudessem representar suas ideias de construção, foi organizada com peças de madeira revestidas de acrílico colorido e pedras dispostas ao lado ou sobre espelhos. Os espelhos possibilitam uma forma de ver diferente o que é construído, de outros ângulos, ampliando as possibilidades do olhar às crianças. Essa organização estética do espaço visa realizar o convite para a brincadeira e exploração das crianças, sem necessitar que o professor dirija o momento. Ao contrário, o professor poderá ocupar o lugar de observador que registra e observa as crianças. Após o momento da construção, as crianças são convidadas a representar graficamente o que construíram.

Figura 1 - Contexto organizado com pedras, peças de madeira com acrílico e espelhos

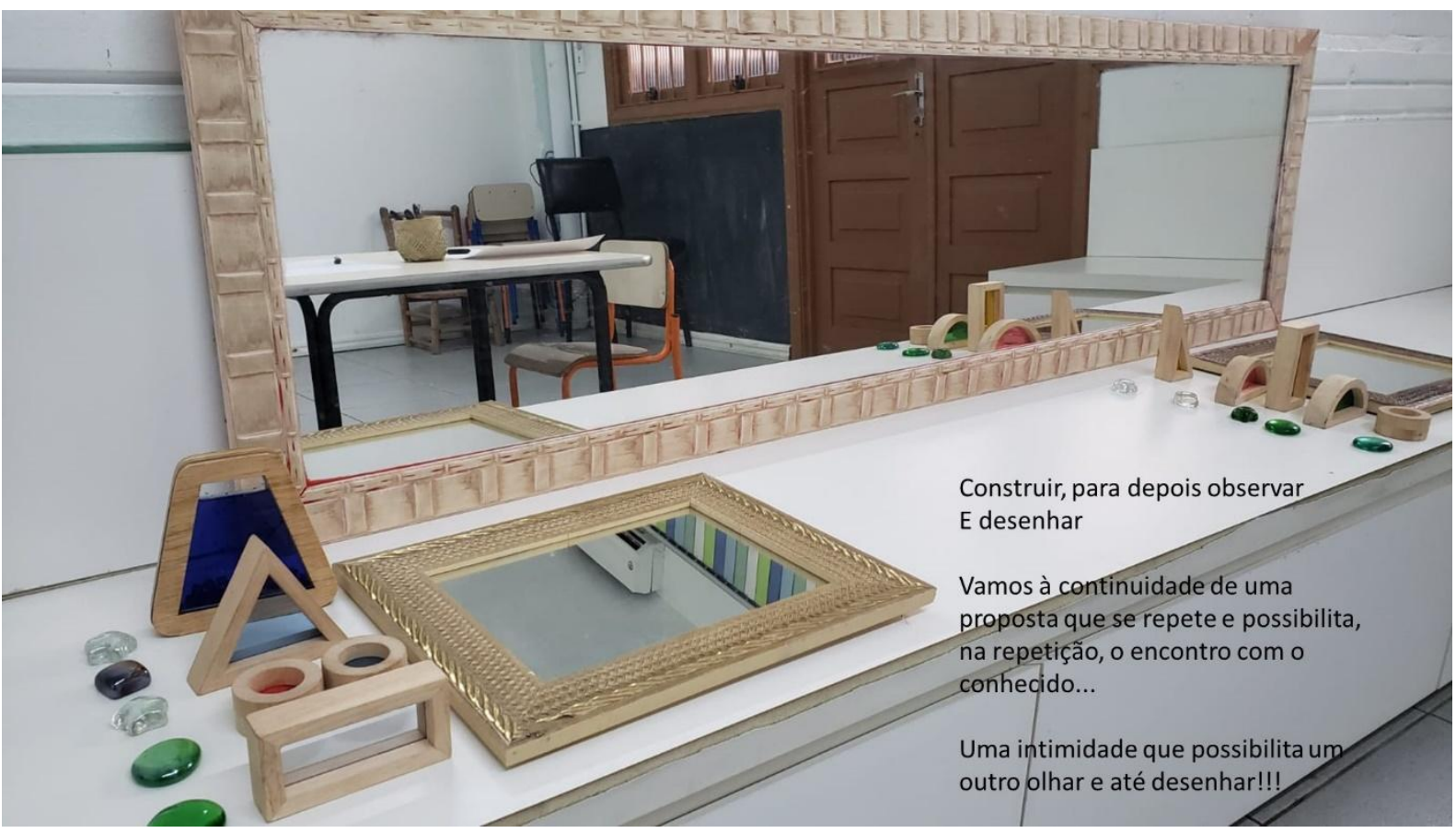

Fonte: Acervo da autora, 2021.

Figura 2 - Contexto organizado com os elementos acima descritos e espaço com canetas e papel para desenho de observação 


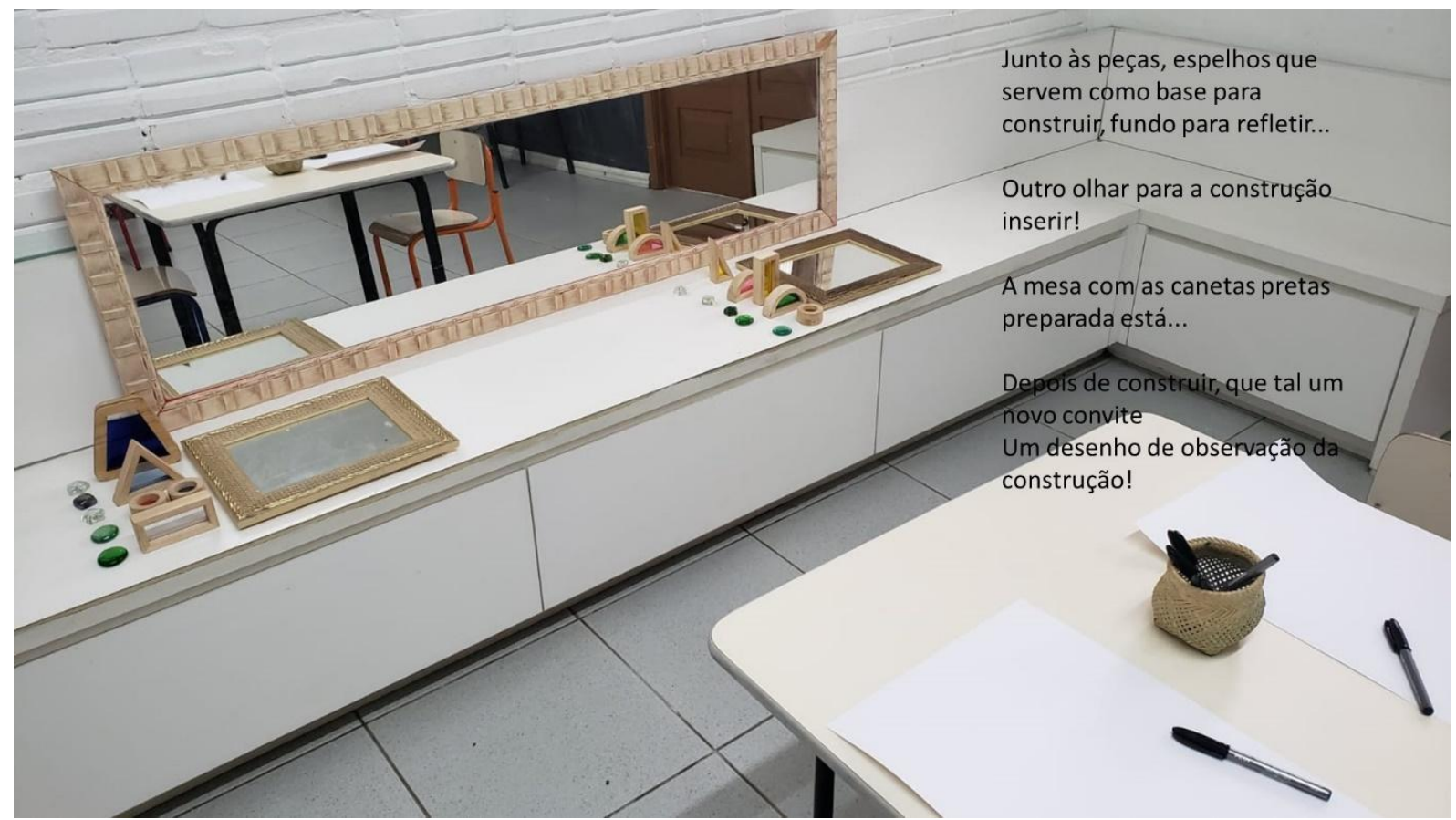

Fonte: Acervo da autora, 2021.

Nessa sessão específica, o olhar da professora volta-se para as ações de Emanuel Elias: um menino que gosta de construir em diferentes ambientes da escola. Na sessão com os materiais não estruturados (pedras, peças de madeira com acrílico e espelho), Emanuel começa a reunir e fazer algo que se assemelha a um retângulo, com uma peça maior do que as outras. Quando termina a construção, pergunto o que ele fez e, então, me responde: "A casa do Lobo, olha ele aqui!" E aponta para a peça maior que está em uma das laterais da forma retangular que construiu. Quando começa a representar graficamente o seu desenho, ele faz lobos, não apenas um, mas três e enquanto desenha, narra o que faz à professora. Além disso, ainda enquanto desenha, narra uma parte da história do Lobo e dos três porquinhos, aquela na qual o lobo assoprou a casa.

Ao observar e registrar as ações de Emanuel, durante a própria sessão já me encanto com sua narrativa, com o que escolhe representar e com seu pensamento expresso no desenho. Faço imagens que, ao voltar, me contam ainda mais do que vi no momento: me narram um menino que se comunica com o desenho, a fala e o corpo todo. Emanuel escolhe construir uma casa e faz referência à casa do lobo, também faz surgir muitos lobos no desenho e narra a voz dos mesmos enquanto vai desenhando. Acompanhar todo o processo, voltar às imagens e poder narrá-las a partir de detalhes que chamam a minha atenção na ação do menino, somente é possível a um professor que, ao organizar um momento com intencionalidade, permitindo-se a 
escuta e o olhar, consegue acompanhar toda a história que envolve Emanuel nessa sessão. Somente o consegue também, pois permite-se não acompanhar e registrar todas as crianças num único dia. Faz uma escolha: nesse dia acompanhará as ações de Emanuel.

Para além de ver individualidades que pertencem apenas ao menino, tenho uma sequência de imagens que me fazem pensar sobre minha prática, sobre como se constitui o desenho para a criança e o quanto o desenho é algo muito além da simples representação. Assim, entendo que desenho é pensamento, é forma de expressão e tem relevância no processo, muito mais do que no resultado final.

Dessa forma, percebo nas mini-histórias um momento de escuta do professor para a fala das crianças, mas também para a sua fala interior que encontra nessa experimentação a oportunidade de tornar pensamento o seu olhar, seu sentir, seu ser. Esses pensamentos evidenciam as dúvidas, as crenças, as descobertas que apenas são possíveis pelo momento do silenciamento, no qual as palavras ressoam o que a alma sente, o que toca, o que experimenta e lhe atravessa, o que provoca emoção.

Figura 3 - Mini-história: Olhar e acompanhar o processo!

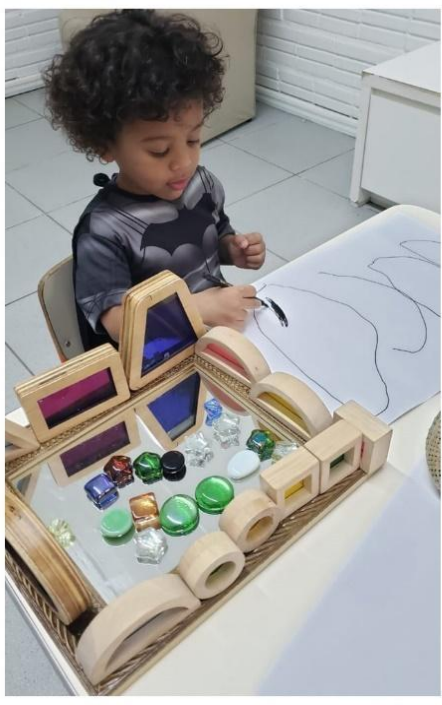

Texto e Imagens: Professoras | Criança: Emanuel Elias(3 a e 1 m) | Agosto de 2021
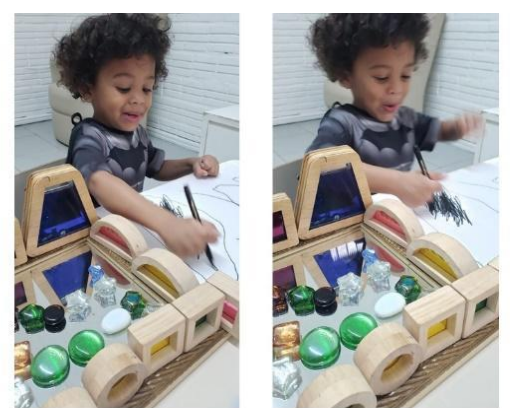

Olhar e acompanhar o processo!!

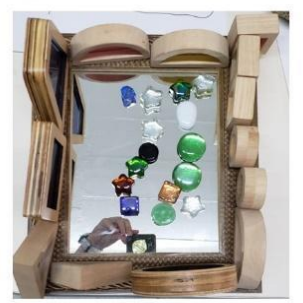

"Eu fiz a casa e o lobo tá aqui, oh!" Essa é a fala de Emanuel Elias e me mostra a peça da sua construção que representa o lobo. Quando o convido para representar sua construção no papel, ele logo começa e me diz "vou fazer o lobo, mais um lobo e mais um!" Enquanto desenha, faz inclusive a fala na qual o lobo se aproxima e sopra! Acompanho encantada seus desenhos, sua fala e suas expressões...essas quando volto para a imagem fotografada me admiro ainda mais. Realmente, não podemos e não devemos reduzir o desenho das crianças à representação, pois há muita narrativa e imaginação para além do produto final. Somente o olhar para 0 processo e para as narrativas das crianças é capaz de capturar todo o seu valor, por isso a importância do nosso registro e reflexão.

Fonte: Acervo da autora, 2021. (Imagens utilizadas com autorização dos responsáveis pelas crianças.)

Em outra semana, organizo nova sessão de construção seguida de desenho de observação. Destaco que a repetição de sessões com a mesma intencionalidade: construir e representar graficamente, acrescentando novos elementos, permite às crianças a intimidade com os materiais e, por isso, novas e interessantes descobertas também surgem. Nessa sessão, alguns 
elementos foram acrescentados: ladrilhos de cores diversas são reunidos aos elementos já conhecidos do grupo. Emanuel participa, novamente, da sessão. Faz uma construção sobre o espelho na qual reúne pedras e ladrilhos. Quando afirma estar pronto, inicia seu desenho de observação.

Segue imagem desse novo contexto da sessão organizada:

Figura 4 - Contexto organizado contendo, agora, também ladrilhos coloridos

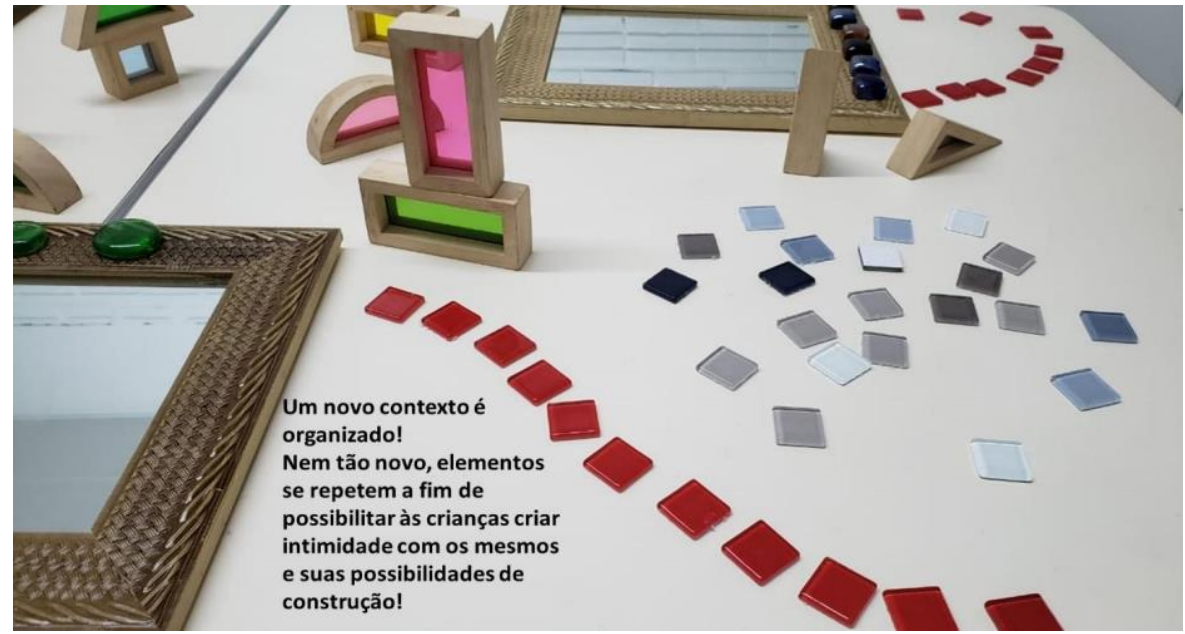

Fonte: Acervo da autora, 2021.

Figura 5 - Mini-história: Uma nova construção, porém com histórias que se repetem!
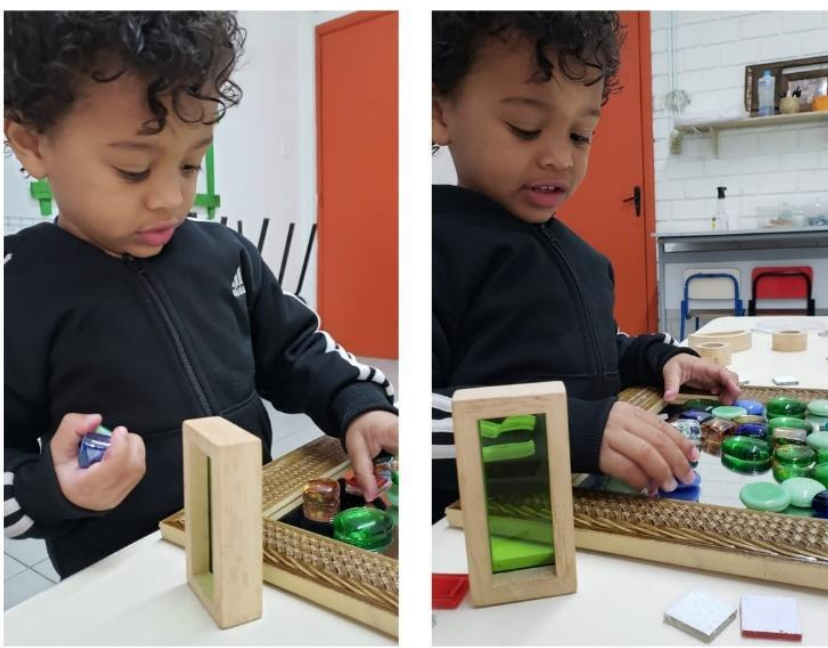

Uma nova construção, porém com histórias que se repetem!
Emanuel Elias escolhe as peças que irão compor sua construção. Em seguida, dispõe e organiza as mesmas sobre a base de espelho.

Um momento no qual ele já participou em outras semanas e, por isso, as peças disponibilizadas na sessão lhe são familiares, o que the possibilita conhecer e tornar-se íntimo das possibilidades de cada peça, bem como suas combinações possíveis.

Após um tempo, pergunto se está pronto e se podemos ir para o desenho de observação.

Ele diz que sim e demonstra desejo de continuar a sua representação agora no plano.

Fonte: Acervo da autora, 2021. (Imagens utilizadas com autorização dos responsáveis pelas crianças.)

Figura 6 - Mini-história: Uma nova construção, porém com histórias que se repetem! (pag. 2) 

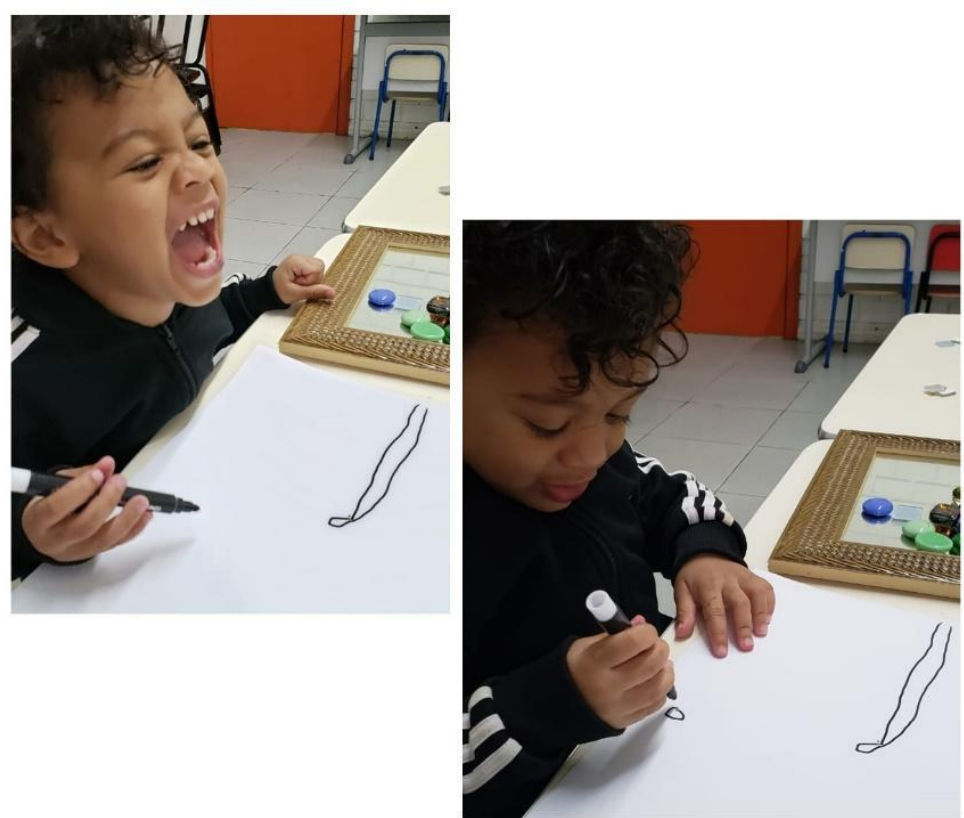

"Eu estou fazendo um monstro e ele faz assim, oh: AHRRRRR"!

Emanuel me mostra com o corpo e a voz que se modifica. Essa mesma voz se torna forte para mostrar a força do monstro que desenhou em sua folha.

Em seguida, continua e me diz: "Vou fazer mais monstros!!"

Logo me lembro da sessão anterior, na qual Emanuel desenha lobos e faz três deles... Hoje também! Assim, evidencia seu interesse por repetir os desenhos, fazer muitos monstros ou lobos...

Acompanhamos o caminho do desenho e do pensamento do nosso menino.

Fonte: Acervo da autora, 2021. (Imagens utilizadas com autorização dos responsáveis pelas crianças.) 
Figura 7 - Mini-história: Uma nova construção, porém com histórias que se repetem! (pag.
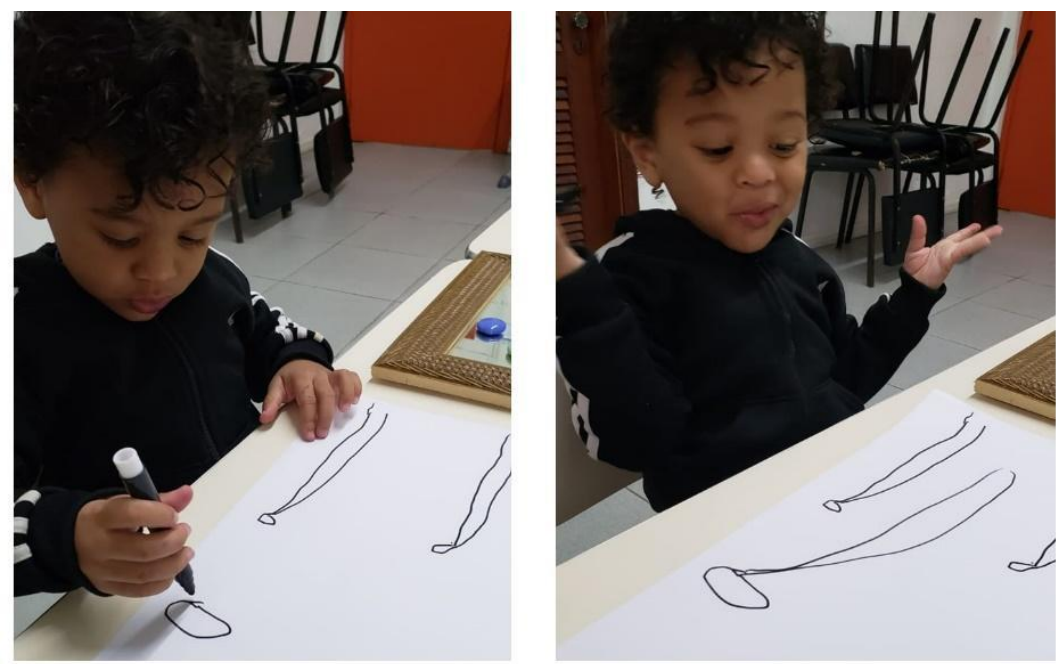

\section{Mas eis que Emanuel volta a desenhar, mais e mais monstros faz na folha de papel habitar!}

E não é que hoje foram três também?!

Assim, vamos registrando e acompanhando a caminhada do menino: quais são suas escolhas de desenho, o que contam do seu pensamento, que traços e linhas se repetem ou se modificam na caminhada.

Sempre atentos ao processo, percebemos as narrativas enquanto histórias do pensar que nos permitem acompanhar a trajetória do nosso menino!

Fonte: Acervo da autora, 2021. (Imagens utilizadas com autorização dos responsáveis pelas crianças.)

Figura 8 -Mini-história: Uma nova construção, porém com histórias que se repetem! (pag. 4)

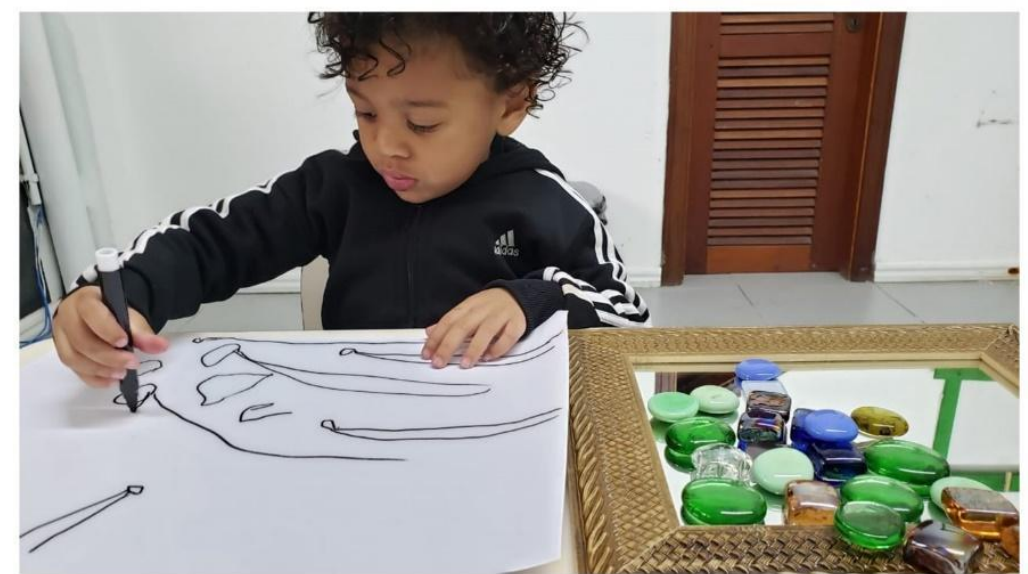

E os monstros não pararam mais de surgir!
Não sei se por desejo de preencher a folha de monstros

Por repetir um desenho e fazê-lo ocupar a folha toda

Pelo tempo que ainda havia para desenhar

Só sei que nosso menino não quis mais parar

E desenhoue

Mais ainda desenhou

Os monstros aumentam

Na medida que aumenta a

Concentração do nosso menino

Voltar a essa história registrada por

imagens

E agora por nós narrada

Faz voar nossos pensamentos Junto com os monstros, os lobos Com nosso menino

Afinal aprendemos com as crianças que a imaginação não tem fim!

Texto e imagens: Professora | Criança: Emanuel Elias (3 a e 2 m) | Setembro de 2021.

Fonte: Acervo da autora, 2021. (Imagens utilizadas com autorização dos responsáveis pelas crianças.)

Nessa nova sessão, Emanuel faz uma construção, mas não a nomeia, apenas começa a narrar enquanto desenha. Semelhante ao que já realizou na sessão anterior, Emanuel escolhe um elemento para representar: nesse dia, os monstros. Os repete na mesma quantidade que 
havia representado os lobos na sessão anterior. Mas depois, talvez pelo tempo que dispunha ou pelo interesse em ocupar mais o espaço da folha, Emanuel faz mais monstros surgirem. Também nessa sessão, enquanto narra seu desenho, faz o som dos monstros, como se desenhar fosse para o menino histórias contar. E talvez, ao pensar no desenho enquanto processo, realmente esse evidencia as histórias narradas pelas crianças. Histórias que se transformam, que têm ou não relação com o que observam e que contam dos enredos que para as crianças têm sentido, daquilo que desejam expressar e o registro gráfico vem a oportunizar.

Pensar as ações dos meninos e das meninas na perspectiva não de dar respostas ou confirmar hipóteses, mas na intenção de ver e perceber correlações entre a prática e a teoria, ou então fomentar perguntas evidenciadas pelas crianças e que não possuem apenas uma única resposta no caminho: o desenho é um exemplo disso. A professora que se põe a pensar sobre o desenho enquanto o mesmo acontece, bem como o lugar e valor que ocupa, pode percebê-lo enquanto linguagem para uma criança que o usa como forma de expressão, mas também o tem como possibilidade de registro e de história do seu pensamento.

Em outra sequência de imagens, escolho olhar para Helena Santos, uma menina que, em primeiro lugar, se percebe na obra que constrói: uma possibilidade ofertada pelo uso do espelho e, depois, quando decide registrar sua construção, o faz contando sobre a baleia. Desenha e verbaliza o que faz. Observo-a na ação, mas quando retomo as imagens, percebo algo que chamou atenção ao meu olhar: as partes do desenho que decide preencher, fazendo grandes pontos pretos em sua baleia, são semelhantes aos lugares que as pedras ocupam no espelho. Mera coincidência? Pode ser, ou não.

Em outro momento, quando repetir a sessão também com Helena, poderei observar o que se repete ou não na ação de desenhar de Helena. Por enquanto, sigo observando, me fazendo perguntas e registrando a fala e o pensamento da menina. Pela mini-história, consigo contar a sua participação no momento organizado: uma história que possui um início, um meio e um fim. Acompanho um momento longo na ação da menina que me permite compreender e pensar sobre o seu processo. Suas ações, interações e seu olhar, me fizeram imaginar o que envolveria as escolhas e os pensamentos da menina. Narrar nos permite também pensar, nos perguntar e ter indícios por onde continuar quando uma nova sessão acontecer e escolhermos os caminhos do desenho de Helena compreender. 
Figura 9 - Mini-história: Olhar, se encantar por na obra estar!

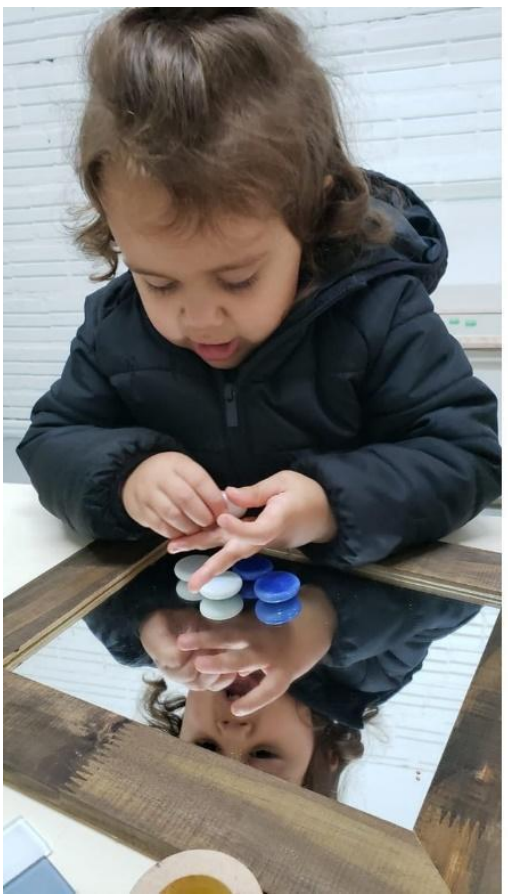

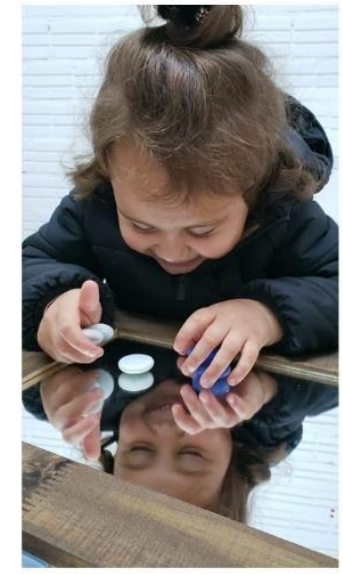

\section{Olhar}

Se encantar

Por na obra estar!!

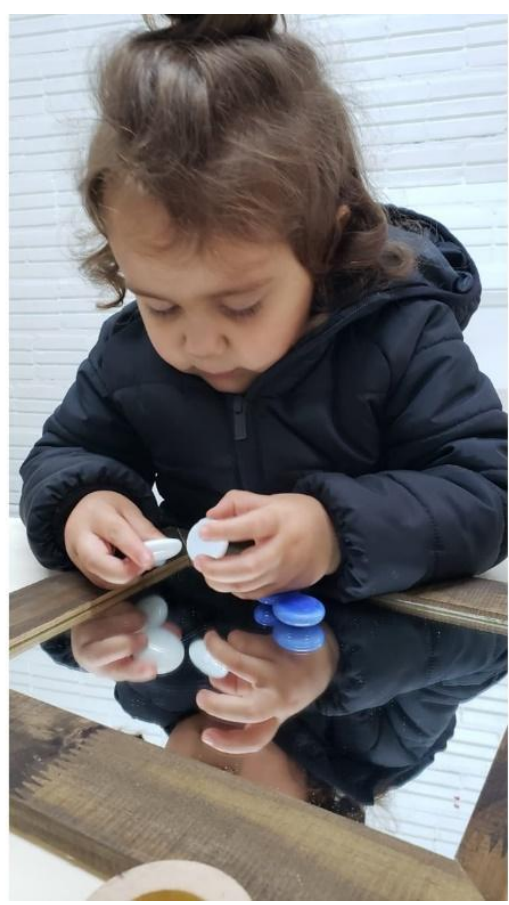

Fonte: Acervo da autora, 2021. (Imagens utilizadas com autorização dos responsáveis pelas crianças.)

Figura 10 - Mini-história: Olhar, se encantar por na obra estar! (pag.2)
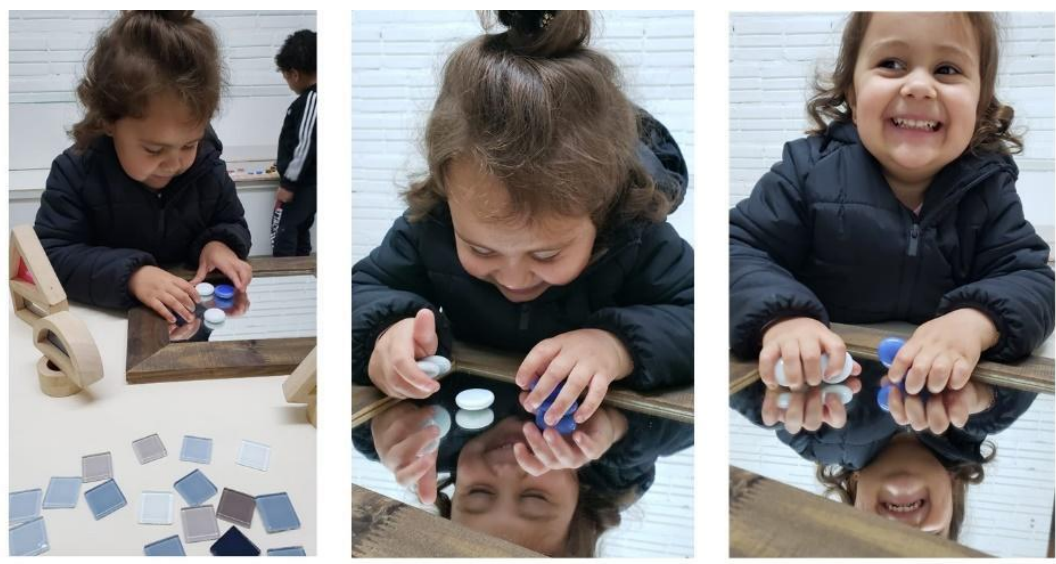

Helena participa pela primeira vez da nossa sessão de construção. Escolhe algumas pedras em tons de azul para compor o que constrói sobre a base de espelho.

Enquanto explora as pedras, divide-se entre a forma que escolhe para construir com elas e o seu olhar que se encanta com sua imagem refletida no espelho. De uma certa forma, ela está inserida no que acaba de construir. Sempre estamos inseridos no que fazemos: nossas histórias, nosso jeito de fazer, conta muito do que somos, do que nos constitui, mas perceber a imagem refletida a fez perceber, visualmente, esse pertencimento e também encantou Helena que, com seu olhar, conversa com o da professora que a observa... Um olhar que conta da sua descoberta e alegria com a mesma.

\section{Estar na sua obra \\ Encanta a menina Helena!}

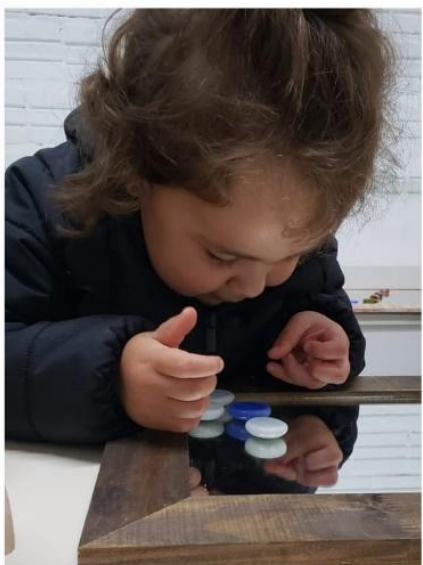

Texto e Imagens: Professora Criança: Helena S.(2 a e $6 \mathrm{~m})$ Setembrode 2021.

Fonte: Acervo da autora, 2021. (Imagens utilizadas com autorização dos responsáveis pelas crianças.) 
Figura 11 - Mini-história: Olhar, se encantar por na obra estar! (pag.3)

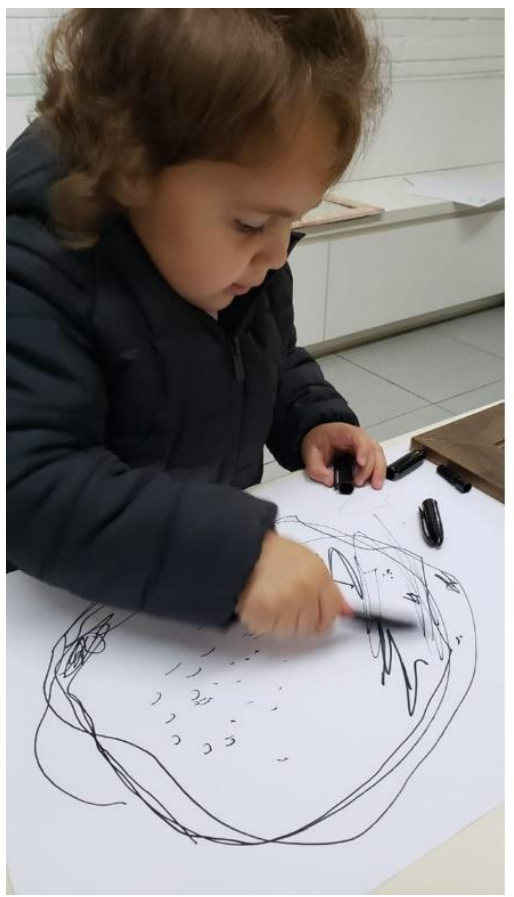

Depois de terminar sua obra, sua construção, convido Helena e seus colegas que participam da sessão para um momento de desenho de observação...

Nesse não acontecem interferências e é a própria criança que conduz o seu registro... a partir do seu olhar. Helena desenha "a baleia". Enquanto desenha me conta do que está a fazer. Por fim, observo que a menina preenche com a caneta preta também alguns pontos do seu desenho, pontos que assemelham-se às pedras que dispôs no espelho. Poderiam ser essa representação?

Talvez sim!

Talvez não!

Apenas uma das muitas formas de ver De perceber que no desenho o processo e a narrativa do mesmo constituem a essência de desenhar

De poder pensar e expressar pensamentos pelo grafismo!

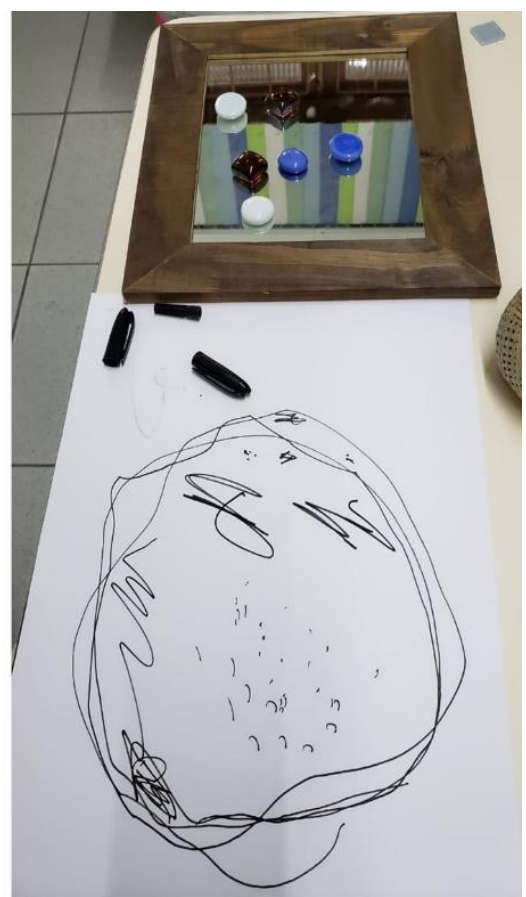

Fonte: Acervo da autora, 2021. (Imagens utilizadas com autorização dos responsáveis pelas crianças.)

Figura 12 - Mini-história: Olhar, se encantar por na obra estar! (pag.4)

Pensar e imaginar

Ações das crianças

Dos adultos que se aventuram a ESCUTAR

Sem julgamentos

Sem pressa

Sem querer ter certeza

Mas com o compromisso de dar voz às ações das crianças

Compromisso de respeitar as crianças

Acreditando que são capazes

Que não precisam de um adulto dirigindo suas ações

E que esse adulto

Pode contribuir

Com a organização de contextos

Orientados por intencionalidades

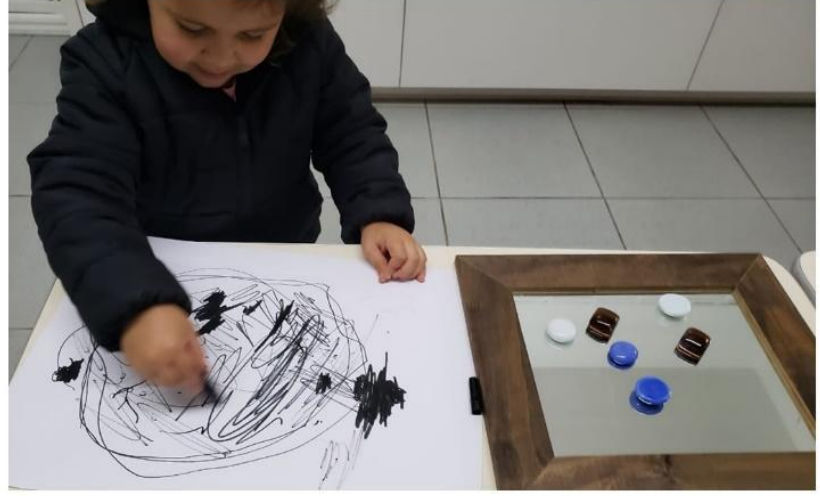

Mas o que desses momentos resultará Somente a criança nos dirá

A ela pertence as escolhas, a forma de se expressar Com o corpo, o olhar, o desenhar

Formas e linguagens das crianças Nem sempre compreendidas pelos adultos

Esses precisam antes de mais nada Exercitar um olhar SEM PRESSA

Um olhar de encanto e maravilhamento

Por tudo o que as crianças nos tem a contar e até ensinar!

Fonte: Acervo da autora, 2021. (Imagens utilizadas com autorização dos responsáveis pelas crianças.)

E assim, narrando, produzindo as mini-histórias, o professor constitui-se, constrói um 
caminho mais leve e mais intenso a partir do olhar que apura o ver, que descobre detalhes e confere sentidos à sua profissão, à medida que encontra nas ações das crianças respostas para a sua ação docente. Nesse sentido, o seu ser professor de crianças pequenas, o seu ser existencial que percebe um sentido no seu cotidiano, ao observar as crianças e sua vida no contexto de uma escola da infância, aprende também a viver.

\section{Referências}

ALTIMIR, David. Como escuchar a la infancia. Barcelona: Octaedro, 2010.

FOCHI, Paulo Sergio. Abordagem da documentação pedagógica na investigação praxiológica de contextos de educação infantil. Relatório para Exame Geral de qualificação em nível de Doutorado. São Paulo, 2017.

LARROSA, Jorge. Tremores: escritos sobre experiência; tradução Cristina Antunes, João Wanderley Geraldi. 1.ed. Belo Horizonte: Autêntica, 2015.

LAZZAROTTO, Gislei D. R.; CARVALHO, Julia D. Afetar. In: FONSECA, Tania Mara Gali; NASCIMENTO, Maria Lívia; MARASCHIN, Cleci. (ORG) Pesquisar na diferença: um abecedário. Porto Alegre: Sulina, 2012, p.23 a 25.

MUNIZ, Adriana Werneck Russo; BASTOS, Karine Oliveira; AMADO, Luiz Antônio Saléh. A escrita como artesanato: a experiência do escrever(-se). Revista Artes de Educar. vol 6, n 3, 2020. Disponível em https://www.e-publicacoes.uerj.br/index.php/riae/article/view/54576. Acesso em 23 out. 2021.

\footnotetext{
' Artigo elaborado a partir do trabalho de conclusão de curso de Pós-Graduação em Artes da UFPEL pela Universidade Aberta do Brasil-UAB, tendo como orientador Professor Cristiano Silveira, Mestre em Educação e Tecnologia.
} 